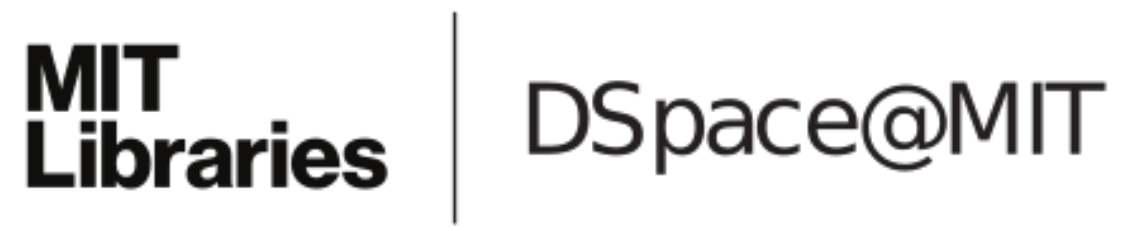

\author{
MIT Open Access Articles
}

Representation of Vegetation in TwoDimensional Hydrodynamic Models

The MIT Faculty has made this article openly available. Please share how this access benefits you. Your story matters.

Citation: Shields, F. Douglas, Kevin G. Coulton, and Heidi Nepf. “Representation of Vegetation in Two-Dimensional Hydrodynamic Models." Journal of Hydraulic Engineering 143, no. 8 (August 2017): 02517002.

As Published: http://dx.doi.org/10.1061/(ASCE)HY.1943-7900.0001320

Publisher: American Society of Civil Engineers (ASCE)

Persistent URL: http://hdl.handle.net/1721.1/119459

Version: Original manuscript: author's manuscript prior to formal peer review

Terms of use: Creative Commons Attribution-Noncommercial-Share Alike 


\title{
Representation of vegetation in two-dimensional hydrodynamic models
}

\author{
F. Douglas Shields, Jr. ${ }^{1}$, Fellow, ASCE, Kevin G. Coulton², Member, ASCE, Heidi Nepf ${ }^{3}$, \\ Member, ASCE
}

\section{Introduction}

Herein we present the work product from an ASCE Task Committee charged with providing a succinct review of the available approaches for determining flow resistance coefficients for vegetated floodplains for use in two-dimensional hydrodynamic model simulations, with comparison of the most promising approaches. In the future, with the restoration and conservation of ecosystems of growing importance, engineers will increasingly design and manipulate floodplain vegetation. Conceivably, the appropriate placement of plants along stream corridors may direct overbank flows, improve flood storage, reduce scour and erosion, facilitate sediment transport, and alleviate other flood risk factors, while also providing critical habitat. Previous approaches to predicting water surface elevations along vegetated channels and floodplains consisted of running computer models that typically allowed little temporal variation in flow resistance coefficients during the course of a flow event. More recently, the sophistication of flow models has improved to allow simulation of interactions among hydraulic variables and vegetation properties. The literature dealing with the effects of vegetation on open channel flow is vast and growing. Several workers have reviewed the current state of the science (Montakhab et al. 2012; Curran and Hession 2013; Hession and Curran 2013; Dombroski 2014, Zahidi et al. 2014), and the paper by Aberle and Jarvela (2013) summarizes the state-ofthe-art in research on the flow resistance of emergent rigid and flexible floodplain vegetation. This paper compiles and interprets this recent literature, with an focus on the estimation of vegetated floodplain resistance for two-dimensional numerical modeling.

\section{Representation of vegetation in hydrodynamic models}

Vegetation growing on channel boundaries and floodplains has complex and important effects on flow magnitude, the vertical profile of velocity, turbulence regime, sediment transport, and hydraulic roughness (Curran and Hession 2013). Recent research seeks to relate observable properties of floodplain plants to their "hydraulic signatures" and thus provide a rational method for incorporating the dynamic characteristics of vegetative roughness into floodplain models. To date, the research has primarily been at an academic level, and there are no

\footnotetext{
${ }^{1}$ Corresponding author, Shields Engineering, LLC. 850 Insight Park, Suite 134, University, MS 38677, doug2shields@gmail.com

${ }^{2}$ cbec eco-engineering, 943 SE 48th Street, Troutdale OR 97060

${ }^{3}$ Department of Civil and Environmental Engineering, Massachusetts Institute of Technology, 77 Massachusetts Ave., Bldg. 48-216D, Cambridge, MA 02139
} 
practical routines for generating flow-dependent vegetation roughness values and incorporating them into multi-dimensional hydrodynamic models.

Aberle and Jarvela (2013) summarize the state-of-the-art in research on the flow resistance of emergent rigid and flexible floodplain vegetation. They note that flow resistance for vegetated areas can be partitioned into the portion due to the sediment surface and that due to the vegetation. Flow resistance and energy losses due to the granular sediment surface are due to viscous drag on the bed surface and form drag due to individual grains or bed forms. Many formulations exist for characterizing the bed resistance as a function of grain size (e.g. Julien, 2010). Energy losses due to vegetation elements are also associated with viscous and form drag, but whose magnitude depend on plant mechanical properties, topology, age, seasonality, foliage, volumetric and areal vegetation porosities, vegetation density, and patchiness. For practical reasons, existing approaches for relating vegetation characteristics to flow resistance do not incorporate all of these vegetation characteristics. Instead, the vegetation characteristics typically are abstracted to include only plant height, stem density, stem flexibility and several coefficients that are specific to a given plant assemblage or species, and are relatively simple to measure in the field.

The contribution of vegetation to flow resistance is determined by computing the drag force, $F_{d}$, exerted by the vegetation on a control volume of water:

$$
F_{d}=\frac{\rho C_{d} A_{v} U^{2}}{2}
$$

In which

$$
\begin{aligned}
& \rho=\text { density of water, } \mathrm{kg} / \mathrm{m}^{3}, \\
& C_{d}=\text { drag coefficient, } \\
& A_{v}=\text { area of the vegetation projected in the plane perpendicular to the flow direction } \\
& \mathrm{m}^{2} \text {, and } \\
& U=\text { velocity upstream of the vegetation, } \mathrm{m} / \mathrm{s} .
\end{aligned}
$$

For hydrodynamic models, the drag force on individual plants or groups of plants is translated into a coefficient in a uniform flow formula (Manning, Chezy, or Darcy) by jointly solving the uniform flow equation and a force balance for a control volume (e.g. Shields and Gippel 1995). Fundamentals of uniform flow are covered in standard texts (e.g., Chow 1959, French 1985, Chadwick and Morfett 1998), and will be treated lightly here. Flow resistance may be represented by the Darcy $f$ friction factor, the Chezy $C$ or the Manning's $n$-value. These three coefficients are related as follows:

$$
C=\sqrt{\frac{8 g}{f}}=\frac{R_{h}{ }^{1 / 6}}{n}
$$

in which

$$
g=\text { acceleration due to gravity, } \mathrm{m} / \mathrm{s}^{2} \text {, and }
$$


$R_{h}=$ hydraulic radius, $\mathrm{m}$, defined as the cross-sectional area divided by the wetted perimeter.

The Darcy and Chezy equations may be derived from first principles, and Darcy $f$ is dimensionless, while Chezy $C$ has dimensions of $\mathrm{LT}^{-2}$. The Manning formula was derived from an empirical curve-fitting process, and $n$ has dimensions of $L^{-1 / 6}$ (French 1985). The empirical nature of the Manning equation and certain aspects of its performance have been criticized for decades (e.g., Committee on Hydromechanics 1963), but it remains in wide use, particularly in the most common hydrodynamic models (e.g., Brunner 2016a and b). Although the most fundamental treatments link resistance coefficients to channel boundary roughness, use of such coefficients to represent many sources of flow resistance (such as that due to floodplain vegetation) has been practiced for decades.

It has been widely assumed that the impact of vegetation on the velocity distribution within the channel does not alter the resistance associated with other channel features, so the overall flow resistance coefficient can be given as the sum of several independent components. For example, the Manning coefficient, $n$, may be expressed as

$$
n_{\text {total }}=n_{\text {bed }}+n_{\text {bends }}+n_{\text {veg }}
$$

Finding $n_{\text {veg }}$, or equivalent Chezy or Darcy coefficients, requires determination of the drag coefficient, $C_{d}$ and projected area $A_{v}$ (Equation 1), or their equivalents. Determination of the vegetation area, $A_{v}$, presented to the flow by emergent plants is complicated by the vertical variation of $A_{v}$, i.e., $A_{v}$ changes in different ways with distance from the bed depending on plant morphology (Petryk and Bosmajian 1975, Aberle and Jarvela 2013). Further complication arises due to the tendency of flexible plants to bend over as velocity increases, and for plant leaves and overall canopy morphology to streamline as flow velocity increases. The bending of plants in this manner, called reconfiguration, has the important tendency of reducing the vegetation drag, so that the flow resistance coefficients $(n, C, f)$ decrease with increasing flow velocity (Freeman et al. 2000, Wilson et al. 2010, Luhar and Nepf 2011, Schoneboom 2011, Wunder et al. 2011).

\section{Vegetation models}

Analytical approaches for finding resistance coefficients for vegetative roughness may be subdivided into four categories based on whether the vegetation is fully submerged or emergent and whether it is rigid or flexible (Figure 1).

\section{Rigid plants}

Isolated, rigid, cylinders have a drag coefficient (when flow is fully turbulent) of approximately 1.0. Complex collections of cylinders and even more complex plants with branching stems that have wakes that overlap and interfere have widely varying values of $C_{d}$ that are hard to predict. Methods developed by Petryk and Bosmajian (1975) and Arcement and Schneider (1989) may be used to compute total flow resistance coefficients for flows through rigid, emergent vegetation. Field data or estimates are required for the vegetation density. These methods are 
useful for flows across floodplains dominated by larger trees that do not bend over and are not submerged.

Based on early work by Petryk and Bosmajian (1975), Arcement and Schneider (1989) provided the following formula for predicting Manning's $n$-values for shallow flows across wide, densely forested floodplains:

$$
n=n_{0} \sqrt{1+\left(\frac{C_{*} \sum A_{i}}{2 g A L}\right)\left(\frac{K_{n}}{n_{0}}\right)^{2} R_{h}^{4 / 3}}
$$

in which

$$
\begin{aligned}
& n_{0}=\text { Manning's } \mathrm{n} \text { due to flow resistance of unvegetated boundary }=n_{\text {bed }}+n_{\text {bends }} \\
& C^{*}=\text { effective drag coefficient } \\
& A_{i}=\text { frontal area of ith plant blocking flow within a reach of length } L, \mathrm{~m}^{2} \\
& A=\text { cross-sectional area of flow, } \mathrm{m}^{2} \\
& L=\text { reach length, } \mathrm{m} \\
& K_{n}=\text { Manning constant to adjust for units }=1.0 \text { for SI units and } 1.49 \text { for U.S. units. }
\end{aligned}
$$

Arcement and Schneider (1989) present a scatter plot (see their Figure 4) of effective drag coefficient values versus hydraulic radius based on field measurements at 14 sites. A line fit to the plotted values may be used to generate $C^{*}$ values for similar sites:

$$
C^{*}=-9.9532 R+22.529
$$

In which $R$ is the hydraulic radius in feet. The resulting $C^{*}$ values are quite large relative to values published by others. This may relate to the low velocity and shallow depth conditions at the studied sites. Velocities were not reported, but measured data for 14 sites produced hydraulic radii ranging from 0.8 to 1.5 feet. The floodplain flows under consideration traversed densely forested areas almost devoid of undergrowth and flows were not deep enough to encounter tree crowns ( $h<H-H_{c}$, Figure 2), so $A_{i}$ was composed almost entirely of tree trunks and was equal to flow depth times trunk diameter, $D_{s i}\left(A_{i}=h D_{s i}\right)$. More sophisticated approaches allow complex variation of vegetation density and geometry with flow depth to allow for regions near the ground (dominated by stems and little or no canopy) and higher regions (dominated by canopy, yielding higher vegetation densities). $C^{*}$ values ranged from 3.7 to 22.7 , total $n$ values ranged from 0.10 to 0.20 , and the contribution of vegetation to total $n$ $\left(n_{\text {veg }}\right)$ was from 0.03 to 0.11 .

Baptist et al. (2007) proposed an approach for rigid vegetation based on Chezy $C$ : 


$$
\begin{aligned}
& C=\sqrt{\frac{1}{\left(\frac{1}{C_{b}^{2}}\right)+\left(\frac{C_{d}^{M D_{S} h}}{2 g}\right)}} \quad \text { for emergent vegetation }[H>h] \\
& C=\sqrt{\frac{1}{\left(\frac{1}{C_{b}^{2}}\right)+\left(\frac{C_{d} M D_{S} H}{2 g}\right)}+\frac{\sqrt{g}}{\kappa} \ln \frac{h}{H} \quad \text { for submerged vegetation }[H<h]}
\end{aligned}
$$

in which

$C$ and $C_{b}$ are the Chezy coefficients for the total roughness and the contribution of roughness from the bed, respectively,

$M=$ vegetation density (conceptualized as an array of cylinders), stems $/ \mathrm{m}^{2}$

$D_{s}=$ plant stem diameter, $\mathrm{m}$

$H=$ plant height, $\mathrm{m}$

$\kappa=$ von Karman's coefficient, and

$h=$ the flow depth, $\mathrm{m}$.

As noted by Baptist et al. (2007), the main limitation of this model is the assumption that the vegetation can be represented as rigid cylinders, so that the model does not account for complex morphology (e.g. branching) or reconfiguration.

Some observers have suggested that when the vegetation is patchy, Manning's $n$ is strongly correlated with the fraction of the flow cross-sectional area occupied by plants, which is termed the flow blockage ratio, $B$ (e.g. Green 2005):

$$
B=\frac{\sum A_{v i}}{A}
$$

in which $A_{v i}$ is the area within cross-section $A$ that is occupied by the ith region or patch of vegetation. When the velocity within the vegetation is much lower than that in the bare fraction of the channel, total Manning's $n$ can be estimated by assuming no flow through, and thus no drag contribution from, the vegetation (Luhar et al. 2008), so

$$
n=\frac{n_{0}}{(1-B)}
$$

This relation is supported by data provided in Green (2005) and Nikora et al (2008), as discussed in Luhar et al. (2008) and Luhar and Nepf (2013). This approach is only valid in situations in which $B<\approx 0.8$ and for which the assumption of a significantly lower velocity within the vegetated region is valid-for example, dense shrubs or vegetation that grows in dense patches, but is not valid for a distribution of individual plants. This expression uses the assumption that within the area occupied by the vegetation the velocity is very low, compared to the velocity in the bare channel. 
Luhar and Nepf (2013) present another approach better suited to a wider array of vegetation configurations as follows:

$$
\begin{array}{r}
n=K_{n}\left[\frac{C_{d} a h}{2 g}\right]^{1 / 2} h^{1 / 6} \text { for emergent vegetation }[H>h] \\
n=\frac{K_{n} h^{1 / 6}}{\left(\frac{2 g}{C_{v}}\right)^{1 / 2}\left(1-\frac{H}{h}\right)^{3 / 2}+\left(\frac{2 g}{C_{d} a H}\right)^{1 / 2}\left(\frac{H}{h}\right)} \quad \text { for submerged vegetation }[H<h]
\end{array}
$$

in which $a$ is the frontal area of vegetation per volume of vegetated region (e.g. Nepf 2012) and $H$ is the height of the vegetation. The non-dimensional vegetation density $a H$ (also known as a roughness density) can be estimated from the leaf-area index (LAI), which is the sum of all plant surface area per unit bed area (Finnigan 2000). For emergent vegetation, only vegetation segments below the water depth $(h)$ contribute to hydraulic roughness, so that the roughness density is $a h$.

$$
a h=0.5 \mathrm{LAI}\left(\frac{h}{H}\right) \text { for emergent vegetation, and } a H=0.5 \mathrm{LAI} \text { for submerged plants }
$$

LAI may be measured using a variety of direct and indirect methods, including the use of remotely-sensed data (Jarvela 2004). For an array of rigid cylinders (a common model for the trunk region of vegetation), $a=M D_{s}$, making Equation (10) and (11) similar to the Baptist et al. (2007 Equations (6 and 7), respectively. Finally, in Equation (11), $C_{v}$ is the coefficient of friction at the top of the vegetation layer, and $C_{v}=0.005$ to 0.13 based on a collection of data from eleven studies of submerged model vegetation (Cheng 2011). Typically, $C_{d} a H>>C_{v}$, so that the right-hand term in the denominator of (11) makes a negligible contribution.

A different formulation for Manning's $\mathrm{n}$ was derived based on the assumption of a hyberbolic tangent profile of velocity over gravel bed roughness (Katul et al 2002), and this model has been applied to characterize vegetated boundaries in the field (Casas et al. 2010, Abu-Aly et al 2014). A hyperbolic tangent profile has been measured in channels with flexible submerged vegetation in both model systems (Ghisalberti and Nepf 2002) and real rivers (Sukhodolov and Sukhodolova 2010). Although the derivation was conceptually based on velocity profiles over submerged gravel roughness, Katul et al (2002) argue that the resulting equation is valid over the range $h / H$ $=0.2$ to 7 , and provide supporting data for $h / H$ as small as 0.5 .

$$
n=\frac{K_{n} h^{\frac{1}{6}}}{\sqrt{ } g C_{u}\left(1+\frac{\alpha H}{h} \ln \left[\frac{\cosh \left(\frac{1}{\alpha}-\frac{h}{\alpha H}\right)}{\cosh \left(\frac{1}{\alpha}\right)}\right]\right)}
$$

in which

$C_{u}=$ similarity constant (empirically estimated as 4.5 by Katul et al. 2002), and

$\alpha=$ characteristic eddy size coefficient (empirically estimated as 1 for gravel boundaries and 0.5 for a forest canopy (Figure 4 in Katul et al 2002). For vegetated boundaries $\alpha$ is expected to be dependent on vegetation density, $a H$. 


\section{Flexible plants}

Flexible plants present a more complex hydraulic signature than rigid plants because they reconfigure in response to higher velocities. As velocity increases, flexible plants offer reduced flow resistance leading to further increases in velocity, which drives further reconfiguration and changes the dependence of drag on velocity. For rigid plants the drag follows the classic quadratic drag law, with force proportional to velocity squared, but for flexible plants the drag increases with velocity to a power less than 2 (e.g. Jarvela 2004, Luhar and Nepf 2011, Albayrak et al. 2011, Whittaker et al. 2015). Baptist et al. (2007) note that this implies that their equation for resistance (i.e., Equations 6 and 7 above) is less suitable for flexible vegetation, although their comparison with data from flume experiments that included flexible vegetation showed a reasonable fit.

Chen et al. (2009) conducted a series of flume studies examining the behavior of uniform stands of four California native floodplain plant species. They also examined the hydraulic roughness and erosion rates of bare soil under the plant canopy. Manning's $n$ values ranged from 0.013 to 0.020 for bare soils and from 0.026 to 0.137 for vegetated soils. For the plants, flow resistance declined as a linear function of the bulk flow Reynolds' number (as plants reconfigured), with linear slopes and intercepts varying according to plant characteristics (including the presence of foliage). For example, Manning's $n$ for wild rose canopy (June foliage) changed from 0.127 to 0.026 (about $80 \%$ reduction) as the Reynolds number ${ }^{4}$ increased from $0.12 \times 10^{6}$ to $2.1 \times 10^{6}$. Although Chen et al. (2009) provides interesting observations, a predictive approach was not included in their report

A predictive approach suitable for both rigid and flexible plants under either submerged or emergent conditions was developed by the Corps of Engineers in concert with Utah State University (Freeman et al. 2000 and 2002, McKay and Fischenich 2011). The Freeman approach explicitly considers plant bending in response to increasing flow, resulting in decreasing flow resistance due to streamlining and reduced plant cross-sectional area. The weakness of the approach is that it is based on regression equations developed using a limited set of flume data. Development of the approach utilized flume test data involving 27 plant types and combinations of plant species, which were used to generate empirical formulas (Freeman et al. 2000 and 2002) for Manning values. The analysis assumed that the roughness due to vegetation dominated the contribution of bed roughness. Bed roughness (clay and mortar) was estimated to have a Manning's value of 0.020 based on flume experiments without vegetation; however, roughness values reported from the flume test show a combined value for bed and vegetation (Freeman et al. 2000). The empirical formulas contain regression coefficients that were computed for 24 species (Freeman et al. 2002), and different relations were proposed for submerged $(h<0.8 H)$ and emergent $(h>0.8 H)$ vegetation based on experimental observation. However, it should be noted that almost all of the experimental runs featured fully submerged, flexible vegetation.

for $h<0.8 H$ (emergent vegetation)

\footnotetext{
${ }^{4}$ Reynolds Numbers in Chen et al. (2009) were in error. The range of values given here is for corrected Reynolds numbers $=U h / v$ 国国 depth and $v$ is the kinematic viscosity of water.
} 


$$
n=K_{n} 9.159 \times 10^{-5}\left(\frac{E_{S} A_{S}}{\rho A_{i *} u_{*}^{2}}\right)^{0.207}\left(M A_{i *}\right)^{0.0547}\left(\frac{u_{*} R_{h}}{v}\right)^{0.490}\left(\frac{R_{h}^{2 / 3} S^{1 / 2}}{u_{*}}\right)
$$

for $h>0.8 H$ (submerged vegetation)

$$
n=K_{n} 0.183\left(\frac{E_{S} A_{s}}{\rho A_{i *} u_{*}^{2}}\right)^{0.183}\left(\frac{H}{h}\right)^{0.243}\left(M A_{i *}\right)^{0.273}\left(\frac{v}{u_{*} R_{h}}\right)^{0.115}\left(\frac{R_{h}^{2 / 3} S^{1 / 2}}{u_{*}}\right)
$$

in which

$E_{s}=$ plant modulus of stiffness (also referred to as Young's modulus, modulus of elasticity, bending modulus), $\mathrm{N} / \mathrm{m}^{2}$

$A_{s}=$ sum of the cross section area of all of the stems of an individual average plant measured at a height of $H / 4$ above the bed, $\mathrm{m}^{2}$

$A_{i^{*}}=$ the area of the plant in the plane normal to the flow direction, i.e., the area of the plant blocking flow, $\mathrm{m}^{2}$

$$
\begin{aligned}
& u_{*}=\text { shear velocity at bed, } \mathrm{m} / \mathrm{s}=\sqrt{g R_{h} S} \\
& M=\text { plant density (no. of plants (not stems!) } / \mathrm{m}^{2} \text { ) } \\
& v=\text { kinematic viscosity, } \mathrm{m}^{2} / \mathrm{s}, \text { and } \\
& S=\text { energy slope, } \mathrm{m} / \mathrm{m} .
\end{aligned}
$$

The plant characteristics $H, A_{i^{*}}$, and $A_{s}$ are all density-weighted average values that were measured without any bending or distortion due to flow.

The formulas above require the plant modulus of stiffness, $E_{s}$. Species-specific values were measured by Freeman et al. (2000) for the 24 tested species. A regression formula was developed for the stiffness modulus, which is a function of the plant slenderness (ratio of height, $H$ to stem diameter, $D_{s}$ ). Data used to develop this formula represented a range of $H / D_{s}$ values between 3 and 116 .

$$
E_{S}[M P a]=7.648 \times 10^{6}\left(\frac{H}{D_{S}}\right)+2.174 \times 10^{4}\left(\frac{H}{D_{S}}\right)^{2}+1.809 \times 10^{3}\left(\frac{H}{D_{S}}\right)^{3}
$$

A plot of this relationship alongside the measured data for certain genera is presented in Figure 3. When their published, measured values are used for $E_{s}$ instead of values computed using the above regression, Freeman et al. (2002) recommended adjusting $E_{s}$ for tree size by dividing the measured value by the ratio $\left(\frac{H}{D_{S}}\right)^{1.5}$ for their measured specimen and then multiplying by the same ratio, $\left(\frac{H}{D_{S}}\right)^{1.5}$, for the tree in question. However, adjustment of $E_{S}$ values published by others (e.g., Whittaker 2014, Goreham 2009, Cannell and Morgan 1987, Stone et al. 2013) for tree size and age is an open question. Stone et al. (2013) failed to find a statistically significant difference in $E_{s}$ between willows and cottonwoods, and noted specifically that $E_{s}$ did not 
correlate with trunk diameter, height, or crown area. However, Stone et al (2013) also noted that correlations with other plant characteristics, such as specimen age or stem water content, should not be ruled out. Considerable scatter occurs among trees of the same size and species when tested in the field (Stone et al. 2013); at least some of this scatter is due to the growth of "reaction wood," in trees subjected to consistent loads such as isolated individuals in areas of prevailing winds. Studies of the conifer species, red pine (Pinus resinosa) in Maine (Shepard and Shottafer 1992) and New Zealand (Watt et al. 2006, Watt and Branislav 2010) have found wide variation in $E_{s}$ related to wood density, tree age, tree slenderness, leaf area index and early autumn air temperature. Shephard and Shottafer (1992) found a fivefold increase in red pine $E_{s}$ with age over the first 40 years, while Wang and Xie (2014) reported decreasing $E_{s}$ with increasing age for 12- to 40-year-old branches from five deciduous and two evergreen tree species. $E_{s}$ values for wood (lumber) used as construction material reported by Kretschmann (2010) are listed by species and specify a constant moisture content (i.e., 12\%).

Jarvela (2004) proposed the following formula for computing a Darcy $f$ value for vegetative roughness for non-submerged, woody vegetation. Reconfiguration of individual branches and leaves lead to a reduction in $f$ with increasing velocity.

$$
f=4 C_{d X} L A I\left(\frac{U}{U_{X}}\right)^{\chi} \frac{h}{H}
$$

in which

$C_{d x}=$ a species-specific drag coefficient

$U_{x}=$ a reference velocity, $\mathrm{m} / \mathrm{s}$, and

$\chi=$ Vogel exponent, a species-specific parameter accounting for the reconfiguration of branches and leaves in flow.

Although plant stiffness $\left(E_{s}\right)$ is not explicitly considered in this formula, it is embedded in the exponent $\chi$, which characterizes the reduction in drag due to the bending of plant elements. Species dependent values for $\chi(-0.38$ to -0.57$)$ and $C_{d x}(0.43$ to 0.69$)$ are provided for several tree species in Table 2 in Jarvela (2004). Because the friction factor and the velocity are codependent, an iterative approach is required to simulate the flow. It is assumed that the $L A I$ has a uniform distribution over the height of the vegetation, and the factor $h / H$ is added to correct $L A I$ for partial submergence. When plants are fully submerged $(h>H)$, the factor $h / H$ is set equal to 1.0.

Whittaker et al. (2015) presented a model for vegetative drag force and validated the equation using an extensive data set from tests using fully submerged living tree specimens of three species (Alnus glutinosa, Populus nigra and Salix alba) in a large-scale towing tank.

The drag force measured for individual trees fit the model

$$
F=\frac{1}{2} \rho C_{d 0} A_{p 0}\left(\frac{\rho U^{2} V H}{E_{S} I}\right)^{\chi / 2} U^{2}
$$

in which 
$C_{d 0}=$ species-specific "rigid" drag coefficient of vegetation not deformed by flow forces. Values for three tree species with [0.76 to 0.88 ] and without [0.79 to 1.04] foliage are reported in Table 3 of Whittaker et al. (2015)

$A_{p 0}=$ projected area of vegetation not deformed by flow forces on plane perpendicular to flow direction

$V=$ submerged volume of the vegetation, $\mathrm{m}^{3}$, and

$I=$ second moment of area, such that $E_{s} I=$ flexural rigidity. For a circular cross section of diameter $D_{s}, I=\pi D_{s}^{4} / 64$

Table 3 in Whittaker et al (2015) reports the Vogel exponent for trees with (-0.73 to -0.81) and without $(-0.57$ to -0.84$)$ foliage, and Table 1 reports flexural rigidity $E_{s} I=31$ to $664 \mathrm{~N} \mathrm{~m}^{-2}$. From the force on individual trees one can define the Darcy $f$ for flow through a distribution of trees as

$$
f=8 \frac{\langle F\rangle}{s_{x} s_{y} \rho U^{2}}
$$

in which

$\langle F\rangle=$ spatially-averaged drag force per tree, and

$s_{x}$ and $s_{y}$ are the longitudinal and lateral spacing between trees.

\section{Vegetation models within hydrodynamic models}

In practice, two-dimensional hydrodynamic models are usually constructed using measured terrain and bathymetric data. Initially, roughness values are assigned to each grid cell using professional judgment and then adjusted to calibrate the model to observed water surface elevations for a given measured discharge. However, in design projects, suitable calibration data for a future condition (terrain, vegetation, extremely large discharges) may not exist, and engineers must be creative. Since flow models cannot provide a unique solution for both depth and velocity, designers are forced to select one or the other as a performance metric or calibration value.

The work described herein may allow computation of flow resistance coefficients using measured or predicted floodplain/riparian vegetation properties. All approaches outlined above contain one or more parameters to describe vegetation geometry, and those for flexible vegetation also include parameters for the effects of plant bending and deformation. These parameters are unknown for most plant species, and some of the work to date has been based on assuming equal parameter values for all species within a reach and running sensitivity analyses by systematically varying parameter values (Stone and Gillihan 2013). Other researchers have made measurements in flumes using uniform beds of one or a very few species at a time (Freeman et al. 2000 and 2002, Chen et al. 2009, Wunder et al. 2011, Wilson et al. 2010, Aberle and Jarvela 2013, Whittaker et al. 2013, 2015) or have made very intensive studies of plant properties in the field (Manners et al. 2013, Stone and Gillihan 2013). Available 
relations for predicting $n$-values from plant characteristics produce different results for the same set of input conditions (Alkis and Werth 2004). Most approaches require some type of successive approximation to converge on a solution due to the mutual dependence of vegetative roughness and flow hydraulics. Clearly, application of these approaches within large hydrodynamic models will require integration of flow resistance algorithms.

Application of Freeman et al. (2000 and 2002) to floodplains assumes that roughness due to an assemblage of plants may be computed using areal density-weighted averages for plant properties such as plant height and stiffness (McKay and Fishenich 2011). An Excel spreadsheet tool (HYDROCAL) has been developed that facilitates this computation. Some issues arise when applying this approach to situations in which values of the dependent variables are outside the ranges of those used to develop the regression formulas. For example, the formulas for submerged and emergent vegetation do not always give the same value at the boundary $h=$ $0.8 \mathrm{H}$. This problem was addressed by an adjustment of the original (Freeman et al. 2000) formulas which led to Equations 14 and 15 above (Freeman et al. 2002), but the discontinuity still occurs for certain combinations of the input variables. Another problem may arise due to the fact that the weighted average plant height is used to determine whether the emergent (Equation 14) or submerged (Equation 15) formula is applied, even if the plant community is quite diverse with respect to height.

Stone and Gillihan (2013) examined the performance of the Jarvela (2004) and Baptist (2007) routines for roughness implemented within the SRH-2D hydrodynamic model (Dombroski 2014) when used for simulation of four discharges in the San Joaquin River. Both approaches underpredicted water surface elevation and over-predicted velocity relative to calibrated models. Errors varied with discharge, with both methods performing equally for simulated flows.

Recent research has included testing or observation of small-scale vegetation samples. For numerical floodplain models, researchers have attempted to scale up plant coefficients measured in flumes or intensive field studies. For example, Manners et al. (2012) describe a process for finding roughness due to monoculture stands of tamarisk. First, they obtained intensive, ground-based LiDAR scans of 12 plots to fully describe plant geometry. Then they used values of $E_{s}$ from Freeman et al. (2000) to account for stem bending and ran a fine-scale hydrodynamic model (River 2D) of each plot to compute velocity distributions up- and downstream. Using a momentum analysis, they computed the drag force on the vegetation and used this force to develop drag coefficients and Manning's $n$ values. The $n$-values for plots were scaled up to river reach scale using a sophisticated statistical process and airborne LiDAR data.

Abu-Aly et al. (2014) describe development of a meter-scale two-dimensional hydrodynamic model of $\sim 28.3 \mathrm{~km}$ of a gravel/cobble-bed river corridor for flows ranging from 0.2 to 20 times bankfull discharge, with and without spatially distributed vegetation roughness. Manning's $n$ was computed using Equation 13 for $0.2<\frac{h}{H}<7$; grid cells outside that range were assigned $n=$ 0.04. Data from airborne LiDAR were used to measure the height of the floodplain plant canopy and roughness was computed based only on plant height and flow depth. No allowance was made for stem bending or canopy streamlining in higher flows or different behavior of different species. Successive steady state runs of SRH-2D (Dombroksi 2014) were used to study variation of vegetative roughness across a range of flows. 


\section{Comparison of methods to estimate the hydraulic roughness of vegetation}

Manning coefficients for the contribution of rigid vegetative roughness to total roughness $\left(n_{\text {veg }}\right)$ computed using the methods of Arcement and Schneider (1989, Equation 4), Baptist et al. (2007, Equations 6 and 7), Luhar et al. (2008, Equation 9), Luhar and Nepf (2013, Equations 10 and 11) and Katul et al. (2002, Equation 13) are shown in Figure 4. These values were computed by treating flow depth as an independent variable, holding the energy slope constant, and assuming a uniform stand of vegetation with evenly-spaced plants of the same species and dimensions. The values for Manning's $n$ for the bed surface was set to 0.03 . The hydraulic radius was assumed equal to the flow depth in all cases. Values for plant height $(H)$, stem diameter $\left(D_{s}\right)$, stem density $(M)$ and leaf area index $(L A I)$ were set equal to $3.7 \mathrm{~m}, 0.012 \mathrm{~m}, 0.78 / \mathrm{m}^{2}$, and 0.96, respectively, to match those reported by Stone and Gillihan (2013) for a "willow riparian" plant community along the San Joaquin River. The height $\left(H_{c}\right)$ and width $\left(W_{c}\right)$ of the canopy were set to $2.19 \mathrm{~m}$ and $1.10 \mathrm{~m}$, respectively. The species-specific drag coefficient, $C_{d}$, was set to 0.88 and the Vogel exponent, $\chi=\psi$ was set to -0.81 , consistent with values for Salix alba from Whittaker et al. (2015). The value of $U_{x}$ was set to $0.1 \mathrm{~m} / \mathrm{s}$ (Jarvela 2004, Aberle and Jarvela 2013). In the Luhar and Nepf (2013) treatment of the submerged case (Equation 11), the friction coefficient at the interface between vegetation and the overlying flow, $C_{v}$, was set to 0.01 , consistent with the magnitude of values reported by Luhar and Nepf (2013).

The Manning's $n$-values computed using the five rigid vegetation models also show some variation (Figure 4). Note that the Arcement and Schneider (1989) approach was not applied for flow depths, $h>1.5 \mathrm{~m}$, in light of data used to develop it. Comparing to compilations of measured $n$ (e.g. Ree 1949, Wu et al. 1999), the Luhar and Nepf (2013) model best captures the strongly non-linear behavior of $n$ near the transition between emergent and submerged conditions. The behavior is also more weakly reflected in the Baptist relation. Specifically, for emergent conditions $(h / H<1)$ the Manning's $n$ values increase with increasing water depth, which makes physical sense because the area of vegetation contributing to form drag increases with increasing depth for emergent conditions. The trend reverses when the plants become submerged, which is also reflected in the Luhar and Nepf (2013) curve (Figure 4). This also makes physical sense, because as submergence, $h / H$ increases above 1 , a decreasing fraction of water depth is blocked by vegetation. Finally, in Figure $\mathbf{4}$ the Luhar relations are calculated $a=$ $(0.5 \mathrm{LAI}) / H$. If instead the rigid cylinder alternative, $a=m D_{s}$, is used, the Luhar prediction falls close to Baptist (2007), with $n=0.01$ to 0.05 . This highlights the strong dependence of $n$ on the accurate representation of LAI.

Manning coefficients for the contribution of flexible vegetative roughness to total roughness computed using the methods of Freeman et al. (2000 and 2002), Jarvela (2004) and Whittaker et al. (2015) are shown in Figure 5. The Freeman et al. (2002) and Whittaker et al. (2015) formulas explicitly consider plant bending in response to flow by incorporating $E_{s}$. For these computations $E_{s}$ was set equal to 3,320 $\mathrm{MPa}$, consistent with data presented by Stone et al. (2013) and Goreham (2009), and comparable to values for Salix specimens published by Freeman et al. (2000 and 2002), Whittaker (2014) and Whitaker et al. (2013) as shown in Figure 3. Equation 16 was not applied because the value of $H / D_{s}=3.7 / 0.012=308$ exceeds the upper limits for that regression and produces a very large $E_{s}=57,500 \mathrm{MPa}$. 
The three approaches produce widely dissimilar results for relatively shallow flows, but converging results for $h / H>0.8$. The complex behavior exhibited by the Freeman et al. (2002) regression model for emergent vegetation likely reflects the specific behavior of the plant specimens tested in their laboratory flume. The Jarvela (2004) equation produces a nearly linear trend of increasing Manning's $n$ with increasing $h / H$ while the Freeman et al. (2002) and Whittaker et al. (2015) relations display complex response to increasing flow depth as different parts of the vegetation are submerged and vegetation is deformed by flow. When flow depth exceeds $0.8 H$, Manning's $n$ decreases as plants reconfigure. In addition, when the plants become submerged, Manning's $n$ decreases further with increasing water depth, because flow accelerates in the layer over the plants, avoiding the drag of the vegetation layer (Luhar 2013, Folkard 2011), similar to the trend captured by Luhar (2013) for rigid vegetation (Figure 4).

It is useful to note that the range of predicted values shown in Figures 4 and $\mathbf{5}$ [ $n=0.01$ to 0.16 ] is consistent with the range of values determined through numerical model calibration for vegetated terrain [ $n=0.035$ to 0.125$]$ in Stone and Gillihan (2013), suggesting that the $n$ models can predict values within the correct order of magnitude. However, given the variation in results found in Figures $\mathbf{4}$ and $\mathbf{5}$, clear guidelines for selecting one approach over another are difficult to provide. The following observations may prove helpful.

Rigid vegetation. The method described by Arcement and Schnieder (1989) is attractive because it is based on field measurements, but limited to emergent vegetation in relatively shallow depths and very low velocities. The methods suggested by Luhar et al. (2008) and Luhar and Nepf (2013) are also supported by data, but the former is strictly limited to situations where flow through patches of vegetation is negligibly small relative to adjacent unvegetated zones. The latter (Luhar 2013) correctly captures the non-linear trend in $n$, with a maximum at $h / H=1$ (Figure 4).

Flexible vegetation. The relations developed for flexible vegetation might be applied to rigid vegetation as well if the values used for elasticity $\left(E_{s}\right)$ or the Vogel exponent $(\chi)$ are appropriately chosen. However, these species-specific (and perhaps age-specific) constants are available for only a very few species. As shown in Figure 5, $n$-values derived using the three methods examined above converge for submerged plants under the conditions assumed for Figure 5. For shallower relative depths, the Freeman et al. (2002) regression formulas are preferred only for the species and hydraulic conditions they tested. Although the other two methods are also based on specific observations of fewer species, the formulated equations are more general, and some of the data used to develop the Whittaker et al. (2015) relation are from a larger scale flume and larger plant specimens. Evidently the Whittaker and Jarvela relations are tuned to reflect full plant configuration under submerged conditions.

\section{Research}

An enhanced version of the two-dimensional hydrodynamic model currently under production by the Bureau of Reclamation, SRH-2DV, will include the Baptist et al. (2007) and Jarvela (2004) formulas (Dombroski 2014). Plans are for SRH-2DV to eventually have a broad capability to simulate "vegetation kinetics," including, "establishment, growth, and mortality of riparian 
vegetation," and attendant effects on flow and sediment transport. The vegetation algorithm is also slated to be added to the Corps flow models (HEC-RAS).

Several workers have called for field verification of vegetation behavior under high flow loading (Stone et al. 2013, Aberle and Jarvela 2013). Field measurements should extend to larger trees in a range of flow conditions, as the scale of existing laboratory data is necessarily narrow. Although difficult and potentially dangerous due to the nature of flood events, perhaps such data could be obtained during controlled floods or through indirect observations. There is also a need to look at drag-stage relationships over a full flood cycle, as there may be some hysteresis. Damage and bending that occurs during peak flows may not be completely reversible, so that Manning's $\mathrm{n}$ may be lower (at same stage) during receding flow than during the rising limb of the flood. Bed scour may also contribute to vegetation failure, with potential impact on hysteresis (Goreham 2009). Heuristics that simplify the decision regarding whether or not to treat vegetation as flexible or rigid are needed to facilitate composition of software algorithms. Additional measured values of modulus of elasticity for riparian trees of various sizes, ages, and species are needed.

Moving from field efforts aimed at better understanding processes to application, more information is needed regarding the interaction of mesh resolution and spatially distributed roughness parameterization (Casas et al. 2010). Techniques that allow efficient generation of appropriate roughness maps from digital elevation models and LiDAR data sets from floodplains are needed (Smith et al. 2004). Such techniques might include algorithms for estimating selected plant properties based on properties easier to measure remotely such as plant height or canopy diameter (Zahidi et al. 2014). Refined field and modeling techniques should be applied to practical problems incurred when managing forested floodways: What patterns of vegetation provide optimal ecosystem services at acceptable levels of conveyance? What are the effects of succession and stand aging on flow resistance?

\section{Summary and Conclusions}

The literature in this area is burgeoning, and few practitioners have resources to synthesize the reports and data for practical application. At the same time, the demand for this information is increasing as ecologically-driven projects are emerging that feature naturally vegetated floodplains. Furthermore, the utility of two-dimensional models for guiding design and management of these areas is increasing, making their use more common. This overview of currently available approaches for simulating effects of vegetation on flow resistance indicates a need for large-scale prototype tests that include both rigid and flexible vegetation across a range of relative submergence. Such a test would require intense efforts to collect data on plant morphology and flexibility. Advancing technology suggests much of such data may be remotely sensed, but remote-sensing methods will require ground truth. 


\section{References}

Aberle, J. and Jarvela, J. (2013). "Flow resistance of emergent rigid and flexible floodplain vegetation." Journal of Hydraulic Research 51(1), 33-45.

Abu-Aly, T. R., Pasternack, G. B. and Wyrick, J. R. (2014). "Effects of LiDAR-derived spatially distributed vegetation roughness on two-dimensional hydraulics in a gravel-cobble river at flows of 0.2 to 20 times bankfull." Geomorphology, 206, 468-482.

Albayrak, I., Nikora, V., Miler, O., and O'Hare, M. (2011). "Flow-plant interactions at a leaf scale: effects of leaf shape, serration, roughness and flexural rigidity." Aquatic Science 73(1), 267-286.

Alkis, M. H. and Werth, D. E. (2004). "Comparing techniques to estimate roughness due to vegetation." Critical transitions in water and environmental management. Proc., World Water Congress 2004. American Society of Civil Engineers Reston, VA.

Arcement, G. J., Jr. and Schneider, V. R. (1989). "Guide for selecting Manning's roughness coefficients for natural channels and flood plains." Paper 2339. U.S. Geological Survey, Denver, Colorado, 38.

Armanini, A., Righetti, M. and Grisenti, P. (2005). "Direct measurement of vegetation resistance in prototype scale." Journal of Hydraulic Research, 43(5), 481-487.

Baptist, M. J., Babovic, C., Uthurburu, J. R., Mynett, A. and Verwey, A. (2007). “On inducing equations for vegetation resistance." Journal of Hydraulic Engineering, 45(4), 435-450.

Brunner, G.W. (2016a). HEC-RAS River Analysis System 2D Modeling User's Manual. U.S. Army Corps of Engineers Hydrologic Engineering Center. Davis, CA.

Brunner, G.W. (2016b). HEC-RAS River Analysis System Hydraulic Reference Manual. U.S. Army Corps of Engineering Hydrologic Engineering Center. Davis, CA.

Casas, A., S. Lane, D. Yu, G. Benito. (2010). "A method for parameterizing roughness and topographic sub-grid scale effects in hydraulic modeling from LiDAR Data." Hydrol. Earth Syst.

Sci., 14, 1567-1579, 2010 www.hydrol-earth-syst-sci.net/14/1567/2010/doi:10.5194/hess-14$1567-2010$

Cannell, M.G.R. and Morgan, J. (1987). "Young's modulus of sections of living branches and tree trunks." Tree Physiology 3, 355-364.

Chadwick, A. and Morfett, J. (1998). Hydraulics in Civil and Environmental Engineering $3^{\text {rd }}$ Edition. E and FN Spon. London, England.

Chen, Z.Q.R., Levent, M. K., Bandeh, H., Tan, E., Ohara, N., Lorenzato, S., Carlon, J. and Griggs, T. (2009). "Study of the Roughness Characteristics of Native Plant Species in California Floodplain Wetlands,"Final Report to USEPA, March.

ftp://ftp.water.ca.gov/RHJV/Roughness\%20Study\%20Final\%20Report\%202009 June-10.pdf

Cheng N. (2011). "Representative roughness height of submerged vegetation."Water Res. Res., 47:W08517.

Chow, V. T. (1959) Open Channel Hydraulics. McGraw-Hill Book Company, Inc. New York 
Committee on Hydromechanics. 1963. "Friction Factors in Open Channels: Progress Report of the Task Force on Friction Factors in Open Channels of the Committee on Hydromechanics of the Hydraulics Division." Journal of the Hydraulics Division, ASCE 89(2), 97-143.

Curran, J. C. and Hession, W. (2013). "Vegetative impacts on hydraulics and sediment processes across the fluvial system." Journal of Hydrology 505, 364-376.

Dombroski, D. (2014). "A Deterministic Spatially-Distributed Ecohydraulic Model for Improved Riverine System Management." Technical Report No. SRH-2014-26, U.S. Bureau of Reclamation, Denver, CO.

Finnigan, J.J. (2000). "Turbulence in plant canopies." Annu Rev Fluid Mech 32, 519-571.

Folkard, A. M. (2011). "Vegetated flows in their environmental context: A review." Proceedings of the Institution of Civil Engineers-Engineering and Computational Mechanics, 164(1), 3-24.

Freeman, G., Rahmeyer, W. and Copeland, R.R. (2000). "Determination of resistance due to shrubs and woody vegetation." Technical Report No. ERDC/CHL TR-00-25, U.S. Army Corps of Engineers Engineer Research and Development Center, Vicksburg, MS.

Freeman, G. E., Rahmeyer, W. H., and Copeland, R. R. (2002). "Development and application of methodology for determination of hydraulic roughness for vegetated floodplains." Proc., Hydraulic Measurements and Experimental Methods 2002. American Society of Civil Engineers, Reston, VA.

French, R.H. (1985). Open Channel Hydraulics. McGraw-Hill, Inc. New York, New York.

Ghisalberti, M. and Nepf, H. (2002). "Mixing layers and coherent structures in vegetated aquatic flow. "Journal of Geophysics Research: Oceans, 107(C2).

Goreham, John O. (2009). "Bending of woody riparian vegetation as a function of hydraulic flow conditions." UNLV Theses/Dissertations/Professional Papers/Capstones. Paper 75.

Green, J. C. (2005). "Comparison of blockage factors in modelling the resistance of channels containing submerged macrophytes." River research and applications, 21(6), 671-686.

Hession, W. and Curran, J. C. (2013). "The impacts of vegetation roughness in fluvial systems." Treatise on Geomorphology. J. Shroder, D. R. Butler, and C. R. Hupp, eds. Academic Press, San Diego, CA, vol. 12, Ecogeomorphology, pp. 75-93.

Jarvela, J. (2004). "Determination of flow resistance caused by non-submerged woody vegetation." International Journal of River Basin Management, 2(1), 61-70.

Julien, P. Y. (2010). Erosion and Sedimentation, Cambridge University Press.

Katul, G., P. Wiberg, J. Albertson, G. Hornberger (2002). "A mixing layer theory for flow resistance in shallow streams." Water Resources Research, 38(11), 1250, doi:10.1029/2001WR000817

Kretschmann, D. E. (2010). "Mechanical Properties of Wood," Chapter 5 in Forest Products Laboratory. Wood handbook-Wood as an engineering material. General Technical Report FPLGTR-190. U.S. Department of Agriculture, Forest Service, Forest Products Laboratory, Madison, Wisconsin.

Luhar, M., Rominger, J., and Nepf, H. (2008). "Interaction between flow, transport and vegetation spatial structure." Environmental Fluid Mechanics,8(5-6), 423-439. 
Luhar, M., and H. Nepf. 2011. "Flow induced reconfiguration of buoyant and flexible aquatic vegetation." Limnol. Ocean., 56(6):2003-2017, doi:10.4319/lo.2011.56.6.2003

Luhar, M. and Nepf, H. M. (2013). "From the blade scale to the reach scale: A characterization of aquatic vegetative drag." Advances in Water Resources, 51, 305-316.

Manners, R. B., Schmidt, J. C. and Wheaton, J. M. (2013). "Multiscalar model for the determination of spatially explicit riparian vegetation roughness." Journal of Geophysical Research: Earth Surface 118, 1-19.

Mckay, S. K. and Fischenich, J. C. (2011). "Robust prediction of hydraulic roughness." Technical Report No ERDC/CHL CHETN-VII-11. U.S. Army Corps of Engineers. U.S. Engineer Research and Development Center. Vicksburg, MS.

Montakhab, A., Yusuf, B., Ghazali, A. H. and Mohamed, T. A. (2012). "Flow and sediment transport in vegetated waterways: A review." Reviews in Environmental Science Biotechnology $11,275-287$.

Nikora, V., Larned, S., Nikora, N., Debnath, K., Cooper, G., and Reid, M. (2008). "Hydraulic resistance due to aquatic vegetation in small streams: Field study." Journal of Hydraulic Engineering, 134(9), 1326-1332.

Petryk, S. and Bosmajian, G. (1975). "Analysis of flow through vegetation." Journal of Hydraulic Division, ASCE 101(7), 871-884.

Ree, W.O. (1949). "Hydraulic characteristics of vegetation for vegetated waterways." Agr. Eng, 30:184-9.

Schoneboom, T., Aberle, J. and Dittrich, A. (2011). "Spatial variability, mean drag forces, and drag coefficients in an array of rigid cylinders." In Experimental methods in hydraulic research, geoplanet: Earth and planetary sciences. Vol.1, 255-265, P. Rowinski, ed. Springer, Berlin.

Shepard, R.K. and Shottafter, J.E. (1992). "Wood property-age relationship of natural and plantation-grown red pine." Technical Bulletin 149. Maine Agricultural Experiment Station.

Shields, F. D. and Gippel, C. J. (1995). "Prediction of Effects of Woody Debris Removal on Flow Resistance." Journal of Hydraulic Engineering, 121(4), 341-354.

Smith, M.J., Asal, F.F.F., Priestnall, G. (2004). "The Use of Photogrammetry and LIDAR for Landscape Roughness Estimation in Hydrodynamic Studies." Proceedings of International Society for Photogrammetry and Remote Sensing XXth Congress, Istanbul, Turkey, 12-23 July; Volume XXXV, WG III/8. p. 6.

Stone, M. and Gillihan, T. (2013). "Testing of dynamic vegetation roughness routines for SRH2D." Draft Report Prepared for the U.S. Bureau of Reclamation. University of New Mexico. Albuquerque, NM.

Stone, M.C., L. Chen, S.K. Mckay, J. Goreham, K. Acharya, C. Fishenich, and A.B. Stone. (2013). "Bending of submerged woody riparian vegetation as a function of a hydraulic flow conditions." River Research and Applications 29(2), 195-205.

Sukhodolov, A. and Sukhodolova, T. (2010). "Case study: effect of submerged aquatic plants on turbulence structure in a lowland river." Journal of Hydraulic Engineering 136(7): 434-446.

Wang, S. and Xie, B. (2014). "Modeling analysis of the bending modulus of elasticity for branches in the period of dormancy." Journal of Beijing Forestry University 36(6):130-134. 
Watt, M. S., Moore, J. R., Facon, J. P., Downes, G. M., Clinton, P. W., Coker, G., ... and Brown, H. E. (2006). "Modeling environmental variation in Young's modulus for Pinus radiata and implications for determination of critical buckling height." Annals of Botany 98(4):765-775.

Watt, M. S. and Branislav, Z. (2010). "Development of a model describing modulus of elasticity across environmental and stand density gradients in plantation-grown Pinus radiata within New Zealand." Canadian Journal of Forest Research 40(8):1558-1566.

Whittaker, P. (2014). "Modeling the hydrodynamic drag force of flexible riparian woodland." Dissertation for Doctor of Philosophy, Cardiff University, Cardiff, Wales.

Whittaker, P., Wilson, C., Aberle, J., Rauch, H. P., and Xavier, P. (2013). "A drag force model to incorporate the reconfiguration of full-scale riparian trees under hydrodynamic loading." Journal of Hydraulic Research, 51(5), 569-580.

Whittaker, P., Wilson, C. A. M. E and Aberle, J. (2015). "An improved Cauchy number approach for predicting the drag and reconfiguration of flexible vegetation." Advances in Water Resources, 83, 28-35.

Wilson, C. A. M. E., Xavier, P., Schoneboom, T., Aberle, J., Rauch, H. P., Lammeranner, W., Weissteiner, C. and Thomas, H. (2010). "The hydrodynamic drag for full scale trees." River Flow 2010. Dittrich, Koll, Aberle, and Geisehainer, eds. Bundesanstalt fur Wasserbau. Karlsruhe, German.

Wu F., Shen H., Chou Y. (1999). "Variation of roughness coefficients for unsubmerged and submerged vegetation." Journal of Hydraulic Engineering ASCE, 125(9):934-42.

Wunder, S., Lehmann, B. and Nestmann, F. (2011). "Determination of the drag coefficients of emergent and just submerged willows." International Journal of River Basin Management, 9:3-4, 231-236.

Zahidi, I., Yusuf, B., and Cope, M. (2014). "Vegetative roughness estimation for hydraulic modelling: A review." Research in Civil and Environmental Engineering, 2(1), 1-10. 


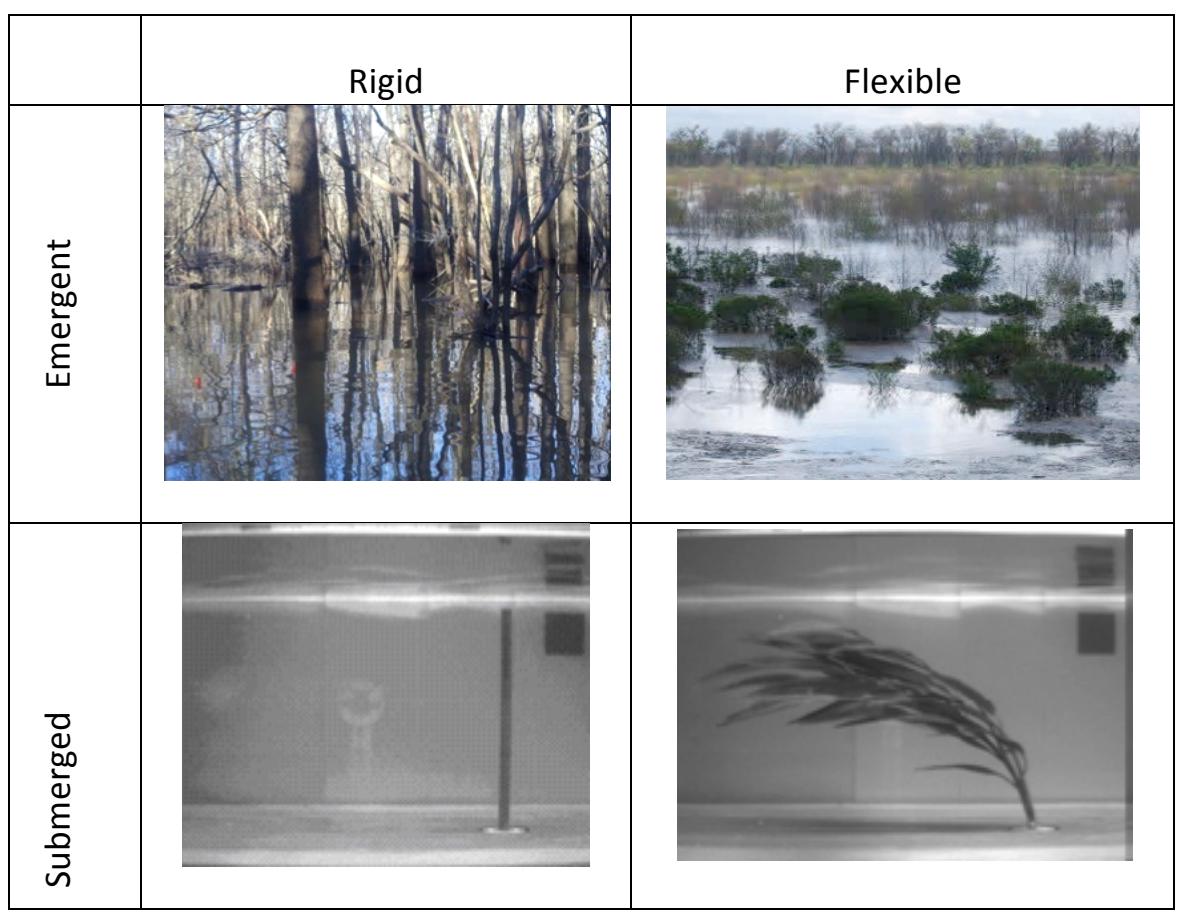

Figure 1. Examples of the four classes of vegetated flows 


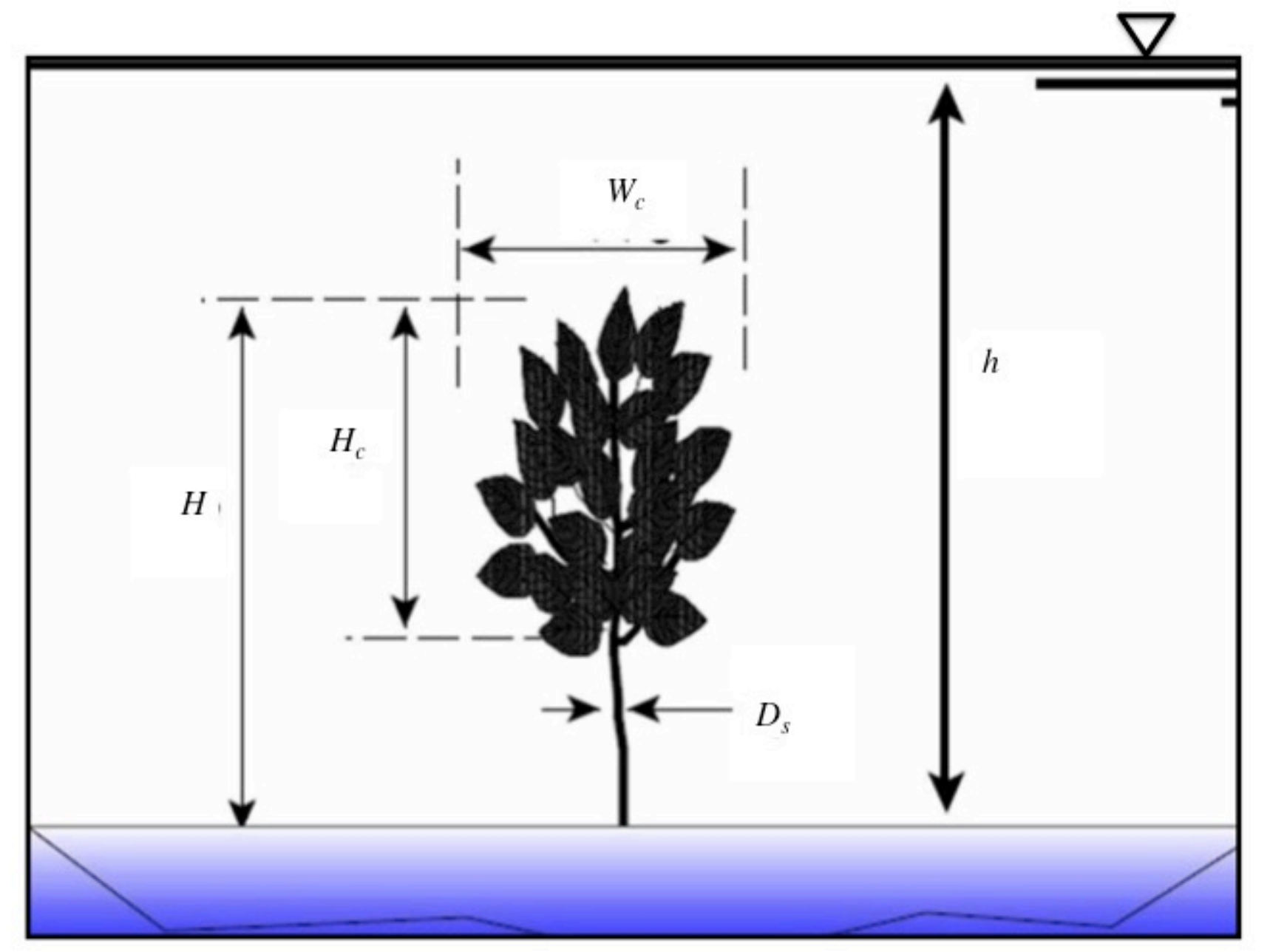

Figure 2. Definition of variables used to specify plant geometry. After Freeman et al. (2000).

Figure 2. Definition of variables used to specify plant geometry. After Freeman et al. (2000). 


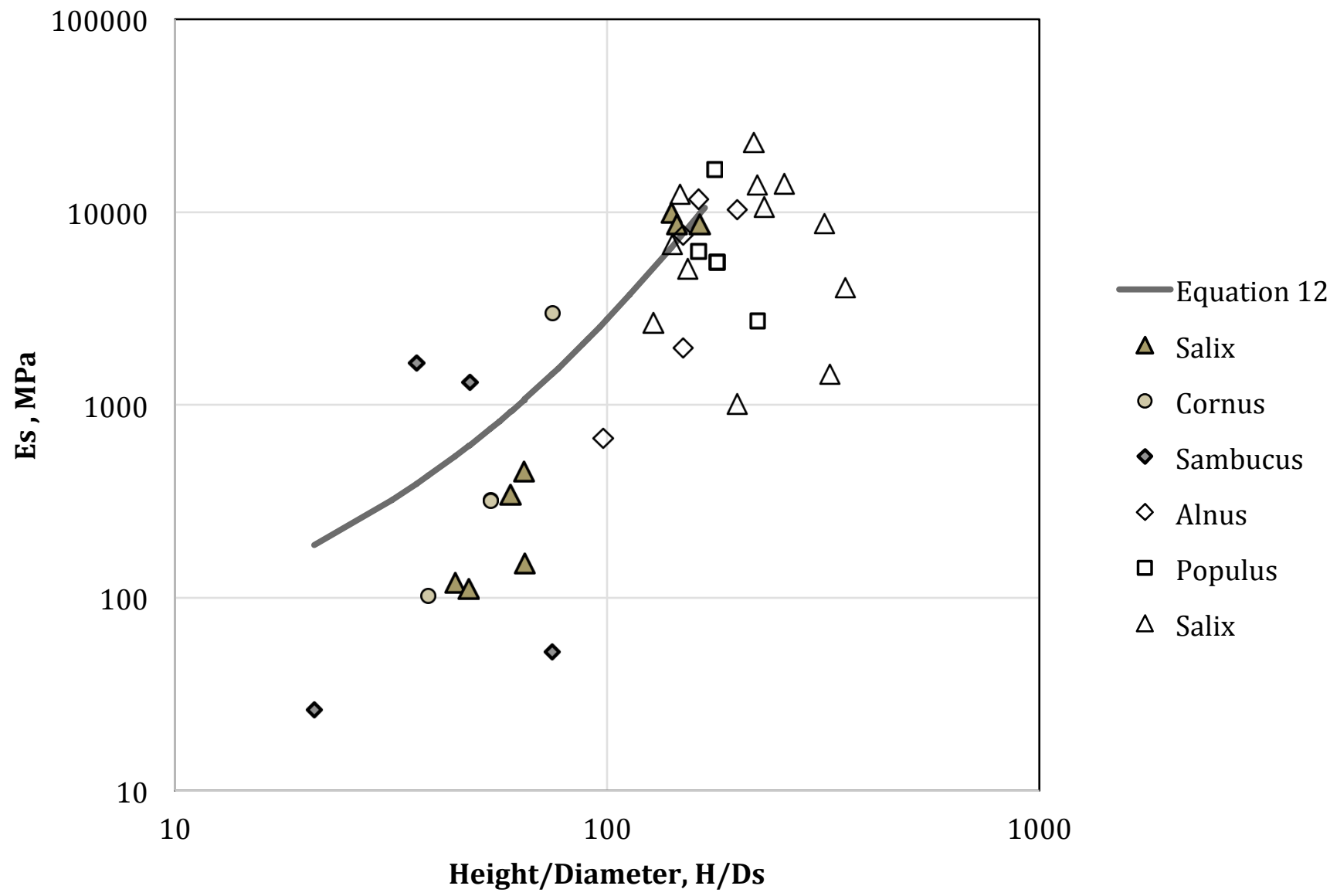

Figure 3. Relationship between tree height/diameter ratio and field-measured $E_{s}$ values published by Freeman et al. (2002) (filled symbols) and Whittaker (2014) and Whittaker et al. (2015) (open symbols). 


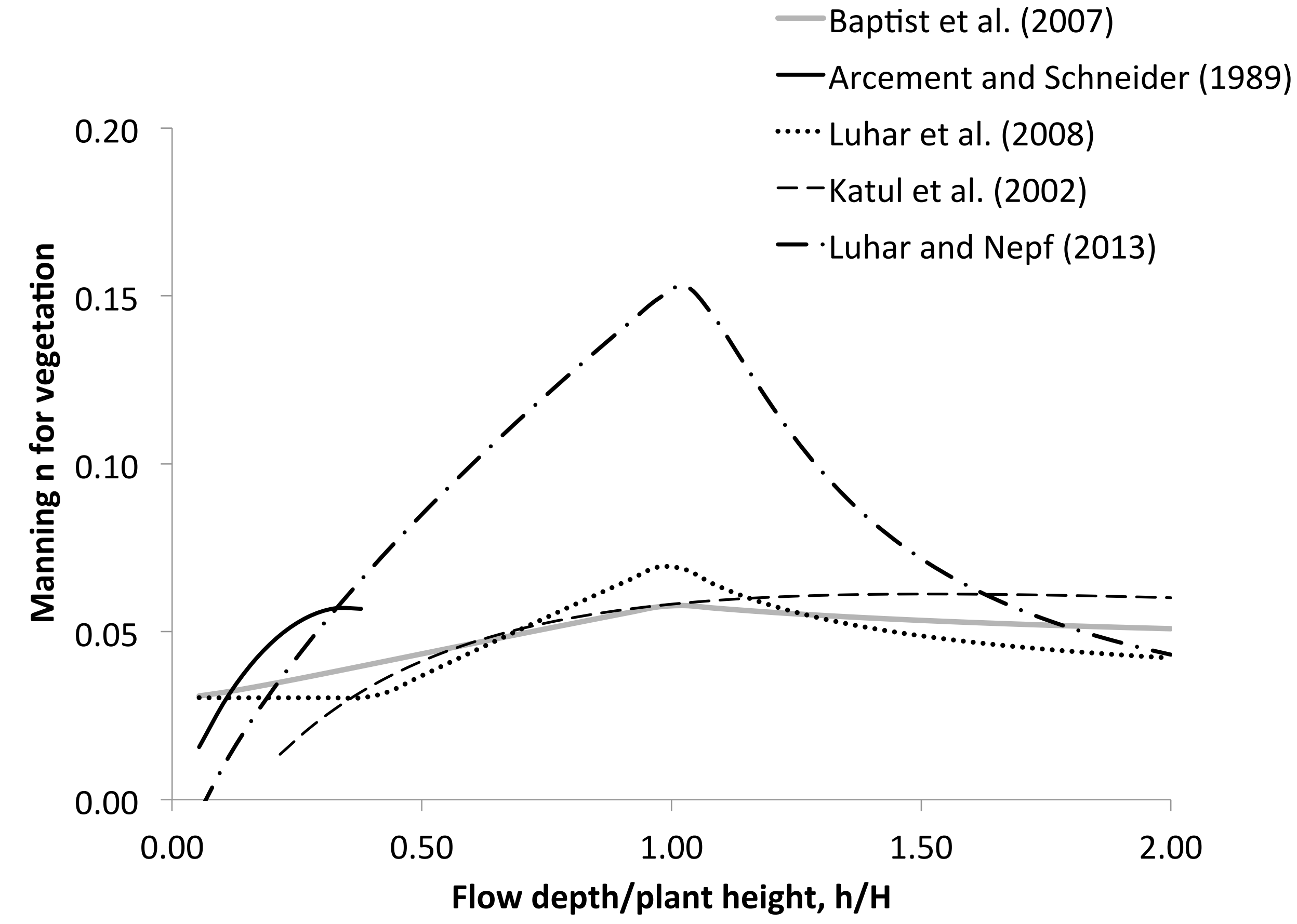


-Arcement and Schneider (1989)

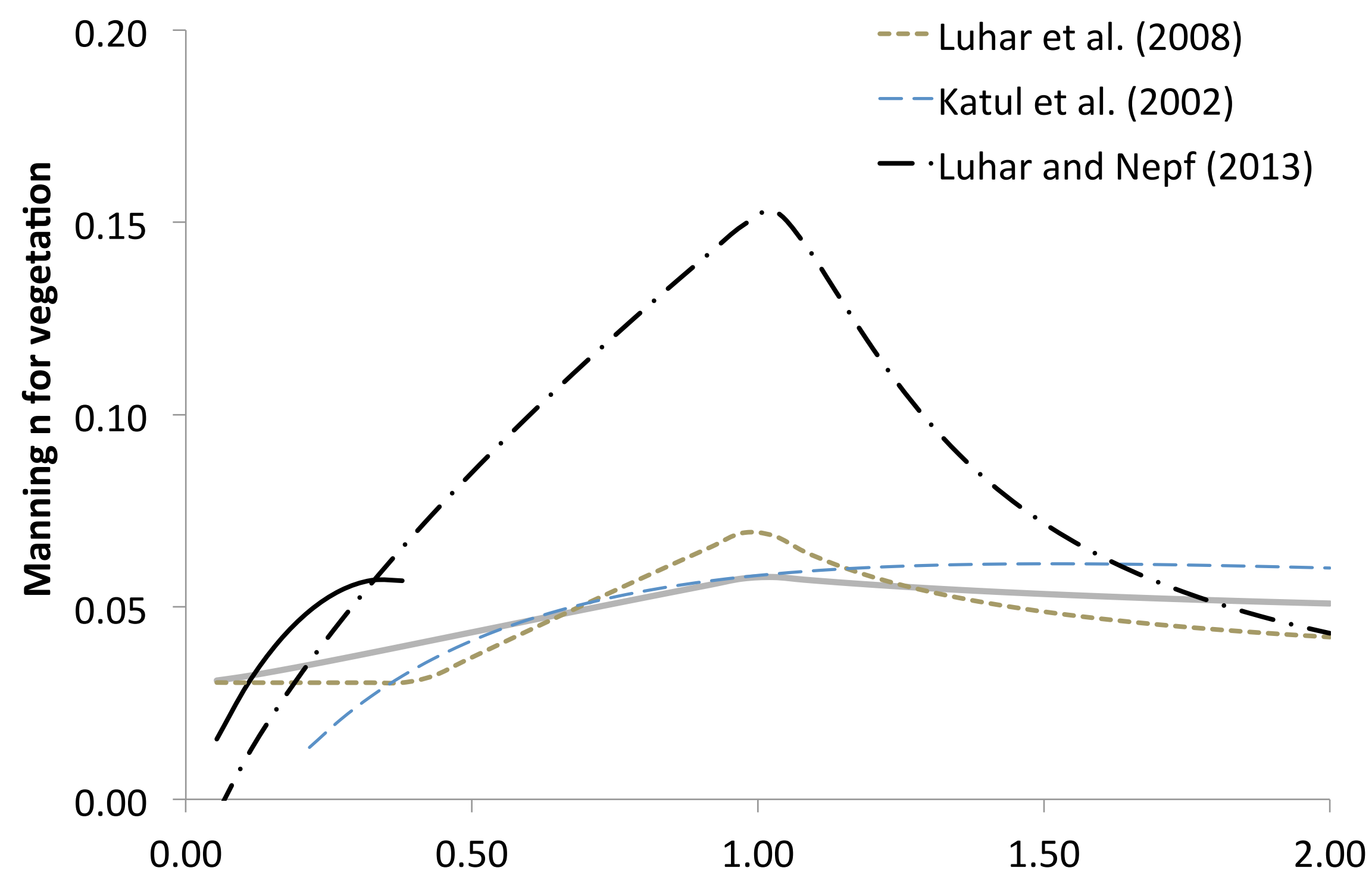

Flow depth/plant height, $\mathrm{h} / \mathrm{H}$ 


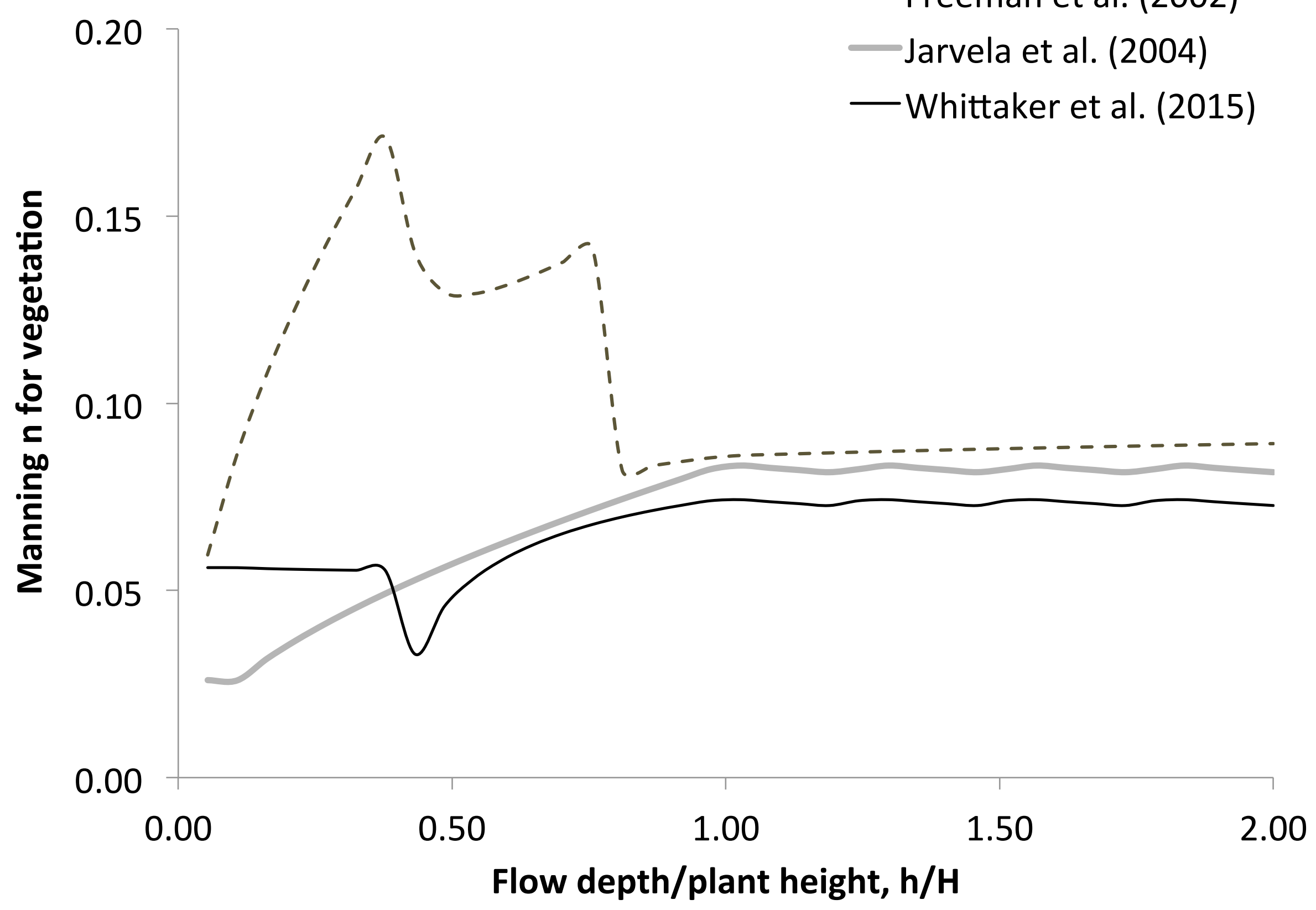




\section{List of figure captions}

Figure 1. Examples of the four classes of vegetated flow.

Figure 2. Definition of variables used to specify plant geometry. After Freeman et al (2000).

Figure 3. Relationship between tree height/diameter ratio and field-measured $\mathrm{E}_{\mathrm{s}}$ values published by Freeman et al. (2002) (filled symbols) and Whittaker (2014) and Whittaker et al. (2015) (open symbols).

Figure 4. Comparison of Manning's n-values for flow through rigid vegetation computed using five approaches.

Figure 5. Comparison of Manning's n-values for flow through rigid vegetation computed using three approaches. 